\title{
Clinician-Patient Communication About Physical Activity in an Underserved Population
}

\author{
Jennifer K. Carroll, MD, MPH, Kevin Fiscella, MD, MPH, Sean C. Meldrum, MS, \\ Geoffrey C. Williams, MD, PhD, Christopher N. Sciamanna, MD, MPH, \\ Pascal Jean-Pierre, PhD, Gary R. Morrow, PhD, MS, and Ronald M. Epstein, MD
}

Background: The 5A (Ask, Advise, Agree, Assist, Arrange) model, used to promote patient behavior changes in primary care, can also be applied to physical activity. Our goal was to assess primary care physicians' use of the $5 \mathrm{~A}$ model in discussions with underserved populations about physical activity.

Methods: We analyzed 51 audio-recorded, transcribed office visits on randomly selected patient care days and after-visit patient surveys with adults in $\mathbf{2}$ community health centers in Rochester, New York.

Results: The patient sample was 51\% African-American and predominantly female (70\%), with the majority having a high school-level education or less (66\%) and an annual household income $<\$ 39,000$ (57\%). Physical activity was discussed during 19 of the 51 visits, which included 16 (84\%) visits with "Ask"; 10 (53\%) with "Advise"; 4 (21\%) with "Agree"; 5 (26\%) with "Assist"; and 0 with "Arrange" statements. Most discussions of physical activity contained several Ask or Advise statements but few Agree, Assist, or Arrange statements.

Conclusion: Communication about physical activity that included Agree, Arrange, and Assist statements of the $5 \mathrm{~A}$ model was infrequent. Health promotion interventions in underserved populations should target these steps and prompt patients to initiate communication to improve physical activity. (J Am Board Fam Med 2008;21:118-127.)

Clinical guidelines, derived from behavioral medicine frameworks, emphasize specific communication strategies for clinicians to effectively counsel their patients about various health habits. A commonly used clinical framework for health behavior counseling is the $5 \mathrm{~A}$ guidelines, shown in Table $1{ }^{1}$ The 5 As paradigm, adapted from the 4As model originally developed by the National Cancer Institute for smoking cessation, has been effectively applied to several other health behaviors and has been endorsed by the United States Preventive Services Task Force as a unifying framework for behavioral counseling in primary care. ${ }^{2-6}$ Previous

This article was externally peer reviewed.

Submitted 2 May 2007; revised 29 October 2007; accepted 1 November 2007.

From the Department of Family Medicine (KF, SCM, PJ-P, RME), the Cancer Center (JKC, KF, PJ-P, GRM, RME), and the Department of Internal Medicine (GCW), University of Rochester, New York; and the Division of General Internal Medicine, Penn State College of Medicine (CNS).

Funding: Funding for this research was supported by Grant R25CA102618 from the National Cancer Institute.

Conflict of interest: none declared.

Corresponding author: Jennifer Carroll, MD, MPH, University of Rochester School of Medicine, Family Medicine Research Programs, 1381 South Avenue, Rochester, NY 14620 (E-mail: Jennifer_Carroll@URMC.Rochester.edu). studies examining the use of the 5 As in communication about diet, exercise, and weight loss in adults $^{7,8}$ found that communication about these behaviors seldom includes offers of assistance (range, 14\% to 17\%) or plans for follow-up (range, $3 \%$ to $10 \%)$. Despite a growing evidence base demonstrating the utility of the $5 \mathrm{~A}$ guidelines, ${ }^{3,9}$ primary care practices-especially those with a large underserved population-may have difficulty implementing it. Competing demands often push primary prevention to the bottom of the agenda for many routine primary care visits. ${ }^{10}$ However, because primary care clinicians are a major source of health behavior advice, there is a need for ways to support clinicians in providing effective counseling.

To design practical interventions to promote effective counseling for physical activity in community-based primary care settings, we need "real-world" data regarding actual communication that occurs; ie, ways in which the 5 As actually translate into clinical practice. Gaps exist in our knowledge of the effectiveness of communication about physical activity with underserved populations, both because we lack these "real-world" examples of specific communication and because we do not fully understand the extent to which 


\begin{tabular}{ll}
\hline Counseling \\
Activity
\end{tabular}

competing demands may influence discussion with underserved populations about physical activity. The goal of our study was to examine the actual language used by primary care physicians when they communicated about physical activity with underserved populations and to analyze that language according to the $5 \mathrm{~A}$ guidelines. We also explored whether patient characteristics or competing demands influenced the discussion of physical activity. Here we define "underserved populations" as groups with low income (eg, $\leq 200 \%$ of the federal poverty level) and/or low educational attainment (eg, less than a high school diploma or equivalent) who may or may not be racial/ethnic minorities.

\section{Methods}

\section{Study Design, Setting, and Participants}

We conducted a cross-sectional observational study of clinicians and their patients at 2 urban community health centers in Rochester, New York. The centers provide primary care to a diverse community of primarily low-income patients, including African-Americans, Asian-Americans, Hispanics, and refugees and immigrants from Africa, Eastern Europe, and Southeast Asia. Twelve of the 13 (92\%) clinicians who provided primary medical care services at the centers ( 8 physicians, 2 physi- cian assistants, and 3 nurse practitioners) participated in the study. Clinicians were informed that the purpose of the study was to observe communication about health in primary care practice. We obtained written informed consent from clinicians before patient recruitment. Then we collected data on the primary outcome variable, the use of the $5 \mathrm{~A}$ model for communication about physical activity, using both direct audio-recording of the visit and a patient survey after the visit.

\section{Patient Recruitment, Enrollment, and Audio-recording of Office Visits}

Patients were recruited from the clinics on randomly selected patient care days. Patients who were 18 years of age or older and were scheduled for a routine, same-day appointment for non-urgent problems or a health maintenance office visit with a participating clinician were told about the study before they met with their clinician. Patients were told that the purpose of the study was to examine communication between patients and their clinicians about health behaviors. Those who expressed an interest in participating met with either the primary investigator or a research assistant $(\mathrm{SF})$ for further discussion and, if they agreed to participate, to give written informed consent. Consented visits were unobtrusively recorded using a digital audio 
recorder. All medical care at the visit was per office routine. Clinicians were not blinded to whether the patient had consented to participate. Neither patients nor clinicians received remuneration for participation. The study was approved by the Research Subjects Review Board of the University of Rochester.

Patients were surveyed at the end of each clinical encounter. The survey consisted of questions regarding patient sociodemographic characteristics, health status and functioning, ${ }^{11,12}$ health behaviors, recall of previous communication with their clinician about physical activity, ${ }^{13}$ and quality of the patient-physician relationship. ${ }^{14}$

\section{Data Coding and Analyses}

We developed a coding and transcription template to capture data from the audio-recorded content of the office visits. Any communication about physical activity or exercise (eg, asking about current exercise or talk about maintaining or changing physical activity behaviors) was coded. We did not use the $5 \mathrm{As}$ as a means to include or exclude discussion of activity, but rather as a means for cataloguing it or describing it when it occurred. Therefore there were no examples of activity discussions that were excluded. For each office visit, any discussion of physical activity was transcribed verbatim as described below. We also coded (1) other topics covered in the visit, (2) whether or not other health behaviors were discussed, and (3) the total duration of the visit.

Research assistants (SF, $\mathrm{AD}$ ) trained by the primary investigator (JKC) listened to all audiotapes of office encounters independently and transcribed any communication about physical activity occurring in the visit to a worksheet. To operationalize the $5 \mathrm{~A}$ guidelines for coding of each $\mathrm{A}$ term in the audiorecorded visits, we defined each A term on our coding templates according to definitions adapted from previous work in the field, ${ }^{3,7}$ as shown in Table 1.

Descriptive statistics (SAS software, version 9.1, SAS Institute, Cary, NC) were used to analyze and report the frequency and content of communication about physical activity. We first computed the sum of each of the $5 \mathrm{~A}$ terms occurring in each office visit based on the transcriptions of the audiorecorded office visits. We used $\chi^{2}$ statistics to examine the association between each $\mathrm{A}$ term and its relationship to certain patient and visit characteristics.

We compared audio-recorded office visit and self-report (survey) data on the 5As to examine the relationship between previous and current communication about physical activity. We qualitatively analyzed the transcripts for which any discussion about physical activity occurred with a manual coding editing approach derived from grounded theory to identify specific examples of the 5 As in communication.

\section{Results}

There were 134 patients scheduled for appointments on days selected for observation. Of those, 64 (48\%) were excluded because they did not meet study criteria (eg, pediatric patients); because they missed their appointment; because of constraints on clinicians' schedules; or because of the lack of an available room. Seventy patients were asked to participate in the study; 51 (73\%) agreed to participate and $19(27 \%)$ refused. The most common reasons for refusal were private/sensitive issues to discuss $(\mathrm{n}=7)$ and lack of time $(\mathrm{n}=5)$.

Table 2 shows patient and clinician participant characteristics. The patient participant sample was largely underserved, as indicated by the racial and ethnic composition, income, and educational levels (Table 2). The clinician participants were all trained in family medicine, predominantly female ( $\mathrm{n}=10 ; 83 \%)$, and were a mix of family physicians $(\mathrm{n}=8 ; 67 \%)$ and either family physician assistants or family nurse practitioners ( $\mathrm{n}=4 ; 33 \%)$. The majority of visits were routine follow-up appointments (ie, 15-min long) with patients' primary care clinicians. Acute visits (eg, for an "urgent care" level problem) were excluded by design.

Of the 51 participants, 49 (96\%) completed the post-visit survey, 47 (92\%) completed observational data, and 44 (86\%) completed both observed visits and the survey. Observational data were missing for 4 of the 51 patients; in 3 cases the equipment malfunctioned and in 1 case the participant intentionally turned off the recorder during the visit.

\section{Use of the 5 A Guidelines for Physical Activity Counseling}

Discussion of physical activity was noted during 19 (41\%) of the 46 audio-recorded/observed patient 
Table 2. Participant Sociodemographic and Health Status Information

\begin{tabular}{|c|c|}
\hline Patient Participants $(\mathrm{n}=12)$ & \\
\hline \multicolumn{2}{|l|}{ Age group (years) } \\
\hline $18-29$ & $12(6)$ \\
\hline $30-39$ & $12(6)$ \\
\hline $40-49$ & $27(13)$ \\
\hline $50-59$ & $20(10)$ \\
\hline $60-69$ & $18(9)$ \\
\hline $70+$ & $8(4)$ \\
\hline Not reported & $2(1)$ \\
\hline \multicolumn{2}{|l|}{ Gender } \\
\hline Female & $71(35)$ \\
\hline Male & $29(14)$ \\
\hline \multicolumn{2}{|l|}{ Race/ethnicity } \\
\hline African-American & $51(25)$ \\
\hline White & $37(18)$ \\
\hline Other & $12(6)$ \\
\hline \multicolumn{2}{|l|}{ Employed } \\
\hline Yes & $33(16)$ \\
\hline No & $35(17)$ \\
\hline Not reported & $33(16)$ \\
\hline \multicolumn{2}{|l|}{ Annual income } \\
\hline$<\$ 12,000$ & $27(13)$ \\
\hline$\$ 12,000-\$ 20,000$ & $20(10)$ \\
\hline$\$ 21,000-\$ 39,000$ & $10(5)$ \\
\hline$\$ 40,000+$ & $8(4)$ \\
\hline Not reported & $35(17)$ \\
\hline \multicolumn{2}{|l|}{ Education } \\
\hline$<12$ years & $29(14)$ \\
\hline High school diploma & $37(18)$ \\
\hline Partial college & $18(9)$ \\
\hline College degree & $14(7)$ \\
\hline Not reported & $2(1)$ \\
\hline \multicolumn{2}{|l|}{ Number of Comorbidities } \\
\hline 0 & $31(15)$ \\
\hline $1-2$ & $31(15)$ \\
\hline $3-4$ & $24(12)$ \\
\hline $5-8$ & $14(7)$ \\
\hline \multicolumn{2}{|l|}{ Common Comorbidities } \\
\hline Diabetes & $27(13)$ \\
\hline Hypertension & $47(23)$ \\
\hline Congestive heart failure & $8(4)$ \\
\hline \multicolumn{2}{|l|}{ Body mass index } \\
\hline $18.5 \geq 24.9$ (normal) & $6(3)$ \\
\hline $25.0 \geq 29.9$ (overweight) & $22(11)$ \\
\hline$\geq 30.0$ (obese) & $53(26)$ \\
\hline Not reported & $18(9)$ \\
\hline \multicolumn{2}{|c|}{ Achieving recommended level of physical activity ${ }^{*}$} \\
\hline Yes & $22(11)$ \\
\hline No & $78(38)$ \\
\hline
\end{tabular}

(Table continues)
Table 2. Continued

\begin{tabular}{lr}
\hline Clinician Participants $(\mathrm{n}=12)$ & \\
\hline Gender & \\
Female & $83(10)$ \\
$\quad$ Male & $17(2)$ \\
Clinician specialty & \\
$\quad$ Physician & $67(8)$ \\
$\quad$ Physician assistant or nurse practioner & $33(4)$ \\
Race/ethnicity & \\
African-American & $25(3)$ \\
Asian & $8(1)$ \\
White & $67(8)$ \\
Years in practice & \\
$\leq 5$ & $33(4)$ \\
$>5$ to $\leq 10$ & $33(4)$ \\
$>10$ to $\leq 15$ & $17(2)$ \\
$>15$ & $17(2)$ \\
Years at health center & \\
$\leq 5$ & $66(8)$ \\
$>5$ to $\leq 10$ & $0(0)$ \\
$>10$ to $\leq 15$ & $17(2)$ \\
$>15$ & $17(2)$ \\
\hline
\end{tabular}

*Two patient participants did not provide survey data.

visits. The 19 visits included 16 (84\%) with "Ask" statements, 10 (53\%) with "Advise" statements, 4 (21\%) with "Agree" statements, 5 (26\%) with "Assist" statements, and none with "Arrange" statements.

\section{Patterns of 5 A Use by Clinicians}

Table 3 shows the clinician-level variability in use of the 5 As for the 19 visits in which the topic of physical activity came up. As Table 3 shows, the pattern of use of the $5 \mathrm{~A}$ terms was fairly evenly distributed among physicians and nonphysicians. Ten $(83 \%)$ of the 12 participating clinicians used an "Ask" statement, 8 (67\%) used an "Advise" statement, 5 (42\%) used "Agree" and "Assist" statements, and none used an "Arrange" statement. The average number of A terms used for both physicians and nonphysicians when the topic of physical activity came up was 2 (range, $0-4$ ). In the 19 visits during which physical activity was discussed, specific activity levels (such as the type, frequency, duration, and/or intensity according to recommended levels ${ }^{15,16}$ ) occurred during just 5 visits. These specific recommendations occurred in the context of advising $(\mathrm{n}=2)$, agreeing $(\mathrm{n}=1)$, and assisting $(\mathrm{n}=2)$. 
Table 3. Patterns of Observed Use of 5 As Among Clinicians

\begin{tabular}{lccccc}
\hline Clinician & $\begin{array}{c}\text { Ask/ } \\
\text { Assess }\end{array}$ & Advise & Agree & Assist & Arrange \\
\hline MD-1 & {$[1]$} & & & {$[12]$} & \\
MD-2 & {$[2]$} & & & & \\
& & {$[11]$} & {$[11]$} & & \\
& {$[13]$} & {$[13]$} & {$[13]$} & & \\
& {$[19]$} & & & & \\
MD-3 & {$[9]$} & & & \\
MD-4 & {$[17]$} & {$[17]$} & {$[17]$} & {$[17]$} \\
MD-5 & & & & \\
MD-6 & {$[14]$} & {$[14]$} & & {$[14]$} \\
& {$[15]$} & {$[15]$} & & \\
MD-7 & {$[3]$} & & & \\
MD-8 & {$[6]$} & {$[6]$} & & \\
NP/PA-1 & {$[18]$} & & & {$[18]$} \\
NP/PA-2 & {$[4]$} & & & \\
& & {$[5]$} & & \\
& {$[7]$} & {$[7]$} & & {$[16]$} \\
& {$[16]$} & {$[16]$} & & \\
NP/PA-3 & {$[8]$} & {$[8]$} & & \\
& {$[10]$} & & {$[10]$} & \\
NP/PA-4 & & & & \\
\hline
\end{tabular}

[n] = visit in which an A term was used among all 19 visits in which physical activity was discussed among the 12 participating clinicians. Visit number is shown to distinguish between multiple visits per clinician with A term used. For example, MD-2 used Ask statements on 3 separate visits, coded as visits [2],[13], and [19].

MD, physician participants; NP, nurse practitioner participant; $\mathrm{PA}$, physician assistant participant.

In those visits during which discussion about physical activity occurred, clinicians tended to do most of the initiating and talking about the topic. In 3 cases $(16 \%$ of the visits during which activity was discussed) the patient initiated the discussion. For visits during which discussion of physical activity occurred, clinician talk usually consisted of 2 or more questions in the "Ask" or "Advise" steps, but comparatively little discussion (typically a single question, sentence, or phrase, if anything) for the "Agree" or "Assist" steps.

Examples of $5 \mathrm{~A}$ statements are provided in $\mathrm{Ta}-$ ble 4. The content of physical activity discussions varied; clinicians mostly provided brief motivational, logistic, or biomedically oriented communication relating the physical activity to patients' specific health conditions. We did not identify any instances of detailed clinician patient communication examining patient-specific barriers or goals with regard to physical activity.

\section{Physical Activity Discussion by Patient and Visit Characteristics}

Table 5 shows patient and visit characteristics and their association with whether or not discussion of physical activity occurred. Visits with discussions of physical activity tended to be longer (median length, $19 \mathrm{~min}$ vs $12 \mathrm{~min}$ ) and to include discussion of more topics (median, 7 topics vs 4 topics) and discussion of other health behaviors in addition to physical activity (Table 5). For example, among patients with whom physical activity was discussed $(\mathrm{n}=19)$, smoking was also discussed in $37 \%$ of cases ( $\mathrm{n}=7$ visits). Smoking was discussed only $24 \%$ of the time in visits which did not include discussions of physical activity. Discussion of physical activity was observed less frequently with African-American patients, obese patients, and patients with fewer comorbidities. Based on patient survey data, only $22.4 \%$ ( $n=11)$ of patients met recommended guidelines for physical activity (3 patients with whom activity was discussed, 8 patients with whom it was not discussed).

\section{Comparison of Audio-recorded Discussion to Patient Recall of Physical Activity Discussion}

Compared with audio-recorded discussion of physical activity, patient self-report (on a survey that asked about recall of $5 \mathrm{~A}$ use in discussion with their primary care clinician) demonstrated a much higher overall incidence of clinician use of each A of the 5 As. Forty-one of the 49 (84\%) patients who completed the questionnaire reported ever having had a discussion with their clinician regarding physical activity. Thirty-two (65\%) patients reported use of an "Ask" statement (eg, "My doctor has asked me about my current activity/exercise habits"); 36 (73\%) an "Advise" statement ("My doctor has given me clear, specific advice to change my activity level/exercise habits"); 37 (76\%) an "Agree" statement ("My doctor and I share in decision making about ways to improve my activity level/exercise habits"); 32 (65\%) an "Assist" statement ("My doctor helped me develop specific ideas, plans, or changes I can make to improve my activity/exercise"); and 25 (51\%) an "Arrange" statement (eg, "My doctor and I made follow-up plans to discuss how I am doing with changing my activity level/exercise"). There was modest agreement between patients and observers as to whether physical activity was discussed during the audio-re- 


\begin{tabular}{|c|c|}
\hline $\begin{array}{l}\text { Statement } \\
\text { Type }\end{array}$ & Examples \\
\hline Ask & $\begin{array}{l}\text { - Clinician: "Exercising three times a week ... that's what you had set as a goal last year in March. How is } \\
\text { that going? ... How much are you thinking you are exercising ... once a week? Once a month?" } \\
\text { - Clinician: "Do you do any sort of exercise?... Anything in particular?" }\end{array}$ \\
\hline Advise & $\begin{array}{l}\text { - Clinician: "You have to do at least half an hour of some kind of motion before it is considered beneficial } \\
\text { to you ... It does help to control your blood pressure ... it helps control your diabetes ... helps } \\
\text { strengthen your bones, makes you less likely to fall ... prevents osteoporosis." } \\
\text { - Clinician: "Try to exercise for three or four times a week. What is walking, what is riding a bike for a } \\
\text { good half an hour at a time ... .cause that will also help." } \\
\text { - Clinician: "What else is good for you is ... getting out and getting to do things that you like to do, } \\
\text { getting some exercise .... getting your body going will help you a little bit as well. (in relation to } \\
\text { depression) If you do this power walk } 5 \text { days a week for a half an hour where you're sweating, eat a } \\
\text { little healthier, more fruits and vegetables and water, less of the bad stuff, you will lose that weight." } \\
\text { Patient: "I'm working on it." }\end{array}$ \\
\hline Agree & $\begin{array}{l}\text { - Clinician: "You did the water flexibility fitness [class]? I'd love to see you go back." } \\
\text { Patient: "Is it still going on?" } \\
\text { Clinician: "Yep, and it'll continue." } \\
\text { Patient: "What day is it? Mondays and Wednesdays?" } \\
\text { Clinician: "Yeah, Mondays and Wednesdays." } \\
\text { Patient: "I'm going back. I don't care if my blood pressure's high or not. I just want to go, cuz see Dr. } \\
\text { X stopped me from going. I was kinda tired; I was kinda glad I had an excuse not to go. But, you } \\
\text { know, I was going - getting up and going, and it was in my schedule. I was going." } \\
\text { Clinician: "I know." }\end{array}$ \\
\hline Assist & $\begin{array}{l}\text { - Clinician: "I found out about this place that does sort of like cardiac rehab. They do a little bit more } \\
\text { intensive follow-up for the weight loss and diabetes and for your heart. They prescribe exercise for } \\
\text { those three reasons. You do well when I see you frequently. When we don't lose contact, I think you } \\
\text { do well. When you have someone on your case, you do a little bit better." } \\
\text { - Clinician: "I think you would be a good candidate because you are doing well with [local exercise } \\
\text { program] and I know when you get excited when you do this .... this weight loss. So I think you'd be } \\
\text { a good candidate for this. So can I refer you there?" }\end{array}$ \\
\hline
\end{tabular}

corded visit: 6 of 19 (32\%) patients with whom some discussion was observed recalled no discussion when interviewed, and 5 of $24(21 \%)$ patients with whom no discussion was observed reported discussion $(\kappa=0.46)$. Patients were much less likely to report that they had received communication from other health care staff (ie, clinic nurses or other health professionals) compared with their recall of discussion with their primary care clinician about physical activity.

\section{Discussion}

Our results show that when clinicians addressed physical activity, their efforts were characterized by an emphasis on 2 As (Asking and Advising), with relatively little use of Agreement (ie, collaborative goal-setting); Assistance (ie, with identifying and overcoming barriers); or Arrangements to help the patient follow through with a physical activity program. There were seldom assessments of patients' willingness to change behavior, and few recommendations were given regarding community resources. These findings are similar to patterns of use of the 5 As in tobacco counseling ${ }^{17-19}$ and in research on diet and exercise counseling in underserved populations. ${ }^{16}$

The finding that the topic of physical activity was raised $41 \%$ of the time was somewhat higher than previously reported in other studies. ${ }^{7,20,36}$ Yet the question of how much counseling is sufficient, and by whom, is an area of active debate. If we consider that the majority of our participants $(78 \%)$ were not meeting recommended levels of activity and/or were either overweight or obese $(75 \%)$, then one could argue that the observed rate of counseling was inadequate to achieve national goals. In all likelihood, a wide variety of strategies in the health care, mass media, policy, and school settings are needed. Intervention studies are also needed to identify efficacy of the $5 \mathrm{As}$ in questioning patients about physical activity, as well as large practical, clinical trials to test the effects of use of the $5 \mathrm{As}$ on physical activity change in primary care settings.

Although primary care clinicians are in a key position to promote physical activity, this task is 
Table 5. Patient and Visit Characteristics in Relation to Visits with and without Observed Discussion of Physical Activity

\begin{tabular}{|c|c|c|}
\hline $\begin{array}{l}\text { Patient and Visit } \\
\text { Characteristics }\end{array}$ & $\begin{array}{c}\text { No } \\
\text { Discussion } \\
\text { of Physical } \\
\text { Activity } \\
(\mathrm{n}=25) \\
(\mathrm{n})\end{array}$ & $\begin{array}{c}\text { Any } \\
\text { Discussion } \\
\text { of Physical } \\
\text { Activity } \\
(\mathrm{n}=19) \\
(\mathrm{n}[\%])\end{array}$ \\
\hline \multicolumn{3}{|l|}{ Age group } \\
\hline $18-39$ & 7 & $5(42)$ \\
\hline $40-59$ & 12 & $8(40)$ \\
\hline $60+$ & 5 & $6(55)$ \\
\hline Not reported & 1 & $0(0)$ \\
\hline \multicolumn{3}{|l|}{ Gender } \\
\hline Female & 17 & $14(45)$ \\
\hline Male & 8 & $5(38)$ \\
\hline \multicolumn{3}{|l|}{ Race/Ethnicity } \\
\hline African-American & 15 & $8(35)$ \\
\hline White & 2 & $3(60)$ \\
\hline Other & 8 & $8(50)$ \\
\hline \multicolumn{3}{|l|}{ Annual income } \\
\hline$\leq \$ 12,000$ & 7 & $4(36)$ \\
\hline$>\$ 12,000$ & 11 & $8(42)$ \\
\hline Not reported & 7 & $7(50)$ \\
\hline \multicolumn{3}{|l|}{ Employed } \\
\hline Yes & 8 & $6(43)$ \\
\hline No & 7 & $8(53)$ \\
\hline Not reported & 10 & $5(33)$ \\
\hline \multicolumn{3}{|l|}{ Body mass index } \\
\hline $18.5 \geq 24.9$ (normal) & 1 & $1(50)$ \\
\hline $25.0 \geq 29.9$ (overweight) & 4 & $6(60)$ \\
\hline$>30.0$ (obese) & 15 & $9(38)$ \\
\hline Not reported & 5 & $3(38)$ \\
\hline \multicolumn{3}{|l|}{ Number of comorbidities } \\
\hline 0 & 11 & $3(21)$ \\
\hline $1-2$ & 6 & $6(50)$ \\
\hline $3=8$ & 8 & $10(56)$ \\
\hline \multicolumn{3}{|l|}{ Years of education } \\
\hline$<12$ years & 6 & $8(57)$ \\
\hline High cchool diploma & 12 & $6(33)$ \\
\hline Any college & 7 & $5(42)$ \\
\hline $\begin{array}{l}\text { Median number of topics } \\
\text { discussed }\end{array}$ & 4 & $7(\mathrm{n} / \mathrm{a})$ \\
\hline $\begin{array}{l}\text { Median number of health } \\
\text { behaviors discussed }\end{array}$ & 1 & $2(\mathrm{n} / \mathrm{a})$ \\
\hline $\begin{array}{l}\text { Median visit duration } \\
\text { (minutes) }\end{array}$ & 12 & 19 (n/a) \\
\hline Total ${ }^{*}$ & 25 & $19(43)$ \\
\hline
\end{tabular}

*Two patients with missing data have been excluded.

challenging in a time-pressured environment with competing priorities, systems barriers, and limited resources. ${ }^{10}$ These issues are magnified for clini- cians working with underserved populations. Nevertheless, we found no evidence that discussion of a large number of concerns diminished the likelihood of physical activity counseling; in fact, the reverse may be true. Although visits in which activity was discussed were longer, they also included nearly twice as many patient concerns. A larger study is needed to assess the relative contribution of the number of patient concerns, demographics, obesity, and race to the likelihood of discussing physical activity.

Previous work has shown that primary care physicians spend an average of approximately $55 \mathrm{sec}-$ onds per visit (though the time varies widely) providing diet and/or exercise advice to patients. ${ }^{20}$ Not surprisingly, fewer than half of patients receiving such advice were able to recall what their physician had said. In one study, an extra minute in the encounter discussing these issues was associated with a 2.5 -fold increase in patient recall. ${ }^{20}$ Perhaps, if more emphasis were placed on strategies or systems to support mutual agreement, setting goals, and specific assistance, clinicians could make better use of their limited time and see improved recall and/or positive behavioral changes in their patients.

Little is known about how the $5 \mathrm{~A}$ model changes patient motivation in regard to physical activity, but based on specific features of the 5As (providing assistance, intratreatment support, access to information about available community resources, and establishing a clear plan for follow-up) seem likely to motivate patients or result in a change of physical activity behaviors. ${ }^{21,22}$ Some of the A terms (mostly the least frequently observed ones: Agree, Assist, and Arrange) aim to set goals collaboratively based on the patient's willingness to change. If patients do not want to change, emphasis may be more appropriately placed on helping the patient connect their behavior to their health; in this way, asking or advising may reinforce patients' responsibility for changing their activity if they believe it will preserve their health. This overlaps conceptually with other behavioral models ${ }^{23-26}$ that promote patient activation to become self-managers more explicitly by providing them with assistance in problem-solving skills.

Despite the multiple barriers to the delivery of high quality counseling, several lines of evidence support a role for expanded physician counseling for physical activity. Randomized clinical trials have found that intensive ${ }^{27}$ and brief $^{21}$ physician 
counseling have been shown to increase physical activity levels in patients, though data on long-term outcomes are lacking. The Activity Counseling Trial found that when physicians were taught how to Ask and Advise patients to promote physical activity and were supported by ancillary staff and office-based systems to provide the other As, they were able to use the model efficiently and achieve a high level of satisfaction from providing it. ${ }^{21}$ The tobacco literature has determined that counseling using the $5 \mathrm{As}$ is 3 times more likely to occur if clinics have support systems to remind physicians to do the counseling. ${ }^{28,29}$ Implementation of office systems to identify sedentary individuals and facilitate the provision of support materials (eg, chart note templates, identification systems for those at risk, and/or community resources lists) might increase counseling for physical activity using the 5As.

Primary care physicians have access to a large portion of the US population; $80 \%$ of adults visit a physician during a 1 -year period, and most of these visits are with primary care physicians. ${ }^{30}$ Patients are often more vulnerable or concerned about their health when visiting a physician and as such are more likely to be receptive and responsive to the information they receive. ${ }^{31}$ Patients find physician counseling useful and it is associated with higher satisfaction with clinical care. ${ }^{32}$ Patients who are advised by a physician to lose weight, quit smoking, eat less fat, and/or become physically active are significantly more likely to attempt to change these behaviors than those who are not advised. ${ }^{33-35} \mathrm{Al}-$ though data from underserved populations are lacking, one study showed that low-income patients with whom physical activity was discussed were significantly more likely to attempt behavior change than were high-income patients. ${ }^{36}$

Some data suggest that the last 2 As (Assist and Arrange) may be better achieved by collaboration with allied health educators, community programs, or other health care staff resources given the competing demands that primary care clinicians face $^{6,15}$ Because strong empirical data to support this are lacking, especially among underserved populations, studies should address the role of ancillary professionals in the delivery of counseling and the effect on activity outcomes.

Interestingly, only one audio-recorded discussion with 4 of the $5 \mathrm{~A}$ terms was patient-initiated. Although very preliminary, this observation sug- gests that patient-initiated discussion about physical activity may be more likely to lead to in-depth conversation (defined as more A terms are covered); thus, clinician training plus patient activation may yield more discussion about physical activity.

Our study has several limitations. First, it was designed to collect a preliminary set of observations to show how the 5 As occur and was conducted at 2 community health centers. We thus had a small sample size in a narrowly defined underserved population, which limits generalizability. Because we used a cross-sectional design, we were unable to assess clinician patient communication about physical activity over time. We attempted to address this shortcoming by incorporating questions about previous communication in the post-visit patient survey, but recall may have been biased, especially given the discordance seen in patient recall compared with actual observed communication. It is possible that the 3 least commonly observed A terms (Agree, Assist, and Arrange) require more patient involvement and dialogue and thus are more time- and effort-intensive for the clinician; we therefore would not have captured these as frequently. We did not include the clinician's perspective on recall or adequacy of communication about physical activity.

Future studies should compare the effects of physician counseling, involvement of other health professionals, and patient activation or prompting of the topic of physical activity outcomes in underserved populations. Only longitudinal studies can measure communication interventions in the "realworld setting" over time, the dose response effect of physical activity discussions, the effect of continuity of care on the $5 \mathrm{As}$, and to test whether $5 \mathrm{~A}$ derived communication interventions result in improved patient behaviors and/or health status.

\section{Conclusion}

Although primary care clinicians in a practice serving an urban underserved population asked and advised about physical activity, very few sought agreement about increasing activity levels, offered specific assistance to patients, or made arrangements to address physical activity. Interventions that support clinicians' efforts directly or via ancillary personnel to address challenges or barriers patients may face, help the patient to set goals and/or change activity levels, discuss specific com- 
munity programs or resources, and make follow-up arrangements to address physical activity may be beneficial. Although training physicians to provide physical activity counseling is important, interventions that encourage patients to prompt their clinicians may further increase clinicians' discussion of physical activity in a manner that motivates behavior change.

We would like to acknowledge our deep appreciation for the support, participation, and enthusiasm of others who participated in the project: Jennifer Yates, who coordinated data organization and tasks related to obtaining relevant references; Stephanie Flecksteiner, Amanda Doyle, Lindsay Heckler, and Noah Harp, who assisted with the coding of the data and conducted literature searches of relevant abstracts and studies; and Margaret Chretien, who graciously assisted with the literature searches. We especially want to extend our sincere thanks to the patients and clinicians who gave freely of their time in the midst of demanding clinical work to support and participate in this project.

\section{References}

1. Glynn TJ, Manley MW. How to help your patients stop smoking: a manual for physicians. NIH Publication 89-3064 ed. Bethesda (MD): National Cancer Institute; 1989.

2. Goldstein MG, Whitlock EP, DePue J, Planning Committee of the Addressing Multiple Behavioral Risk Factors in Primary Care Project. Multiple behavioral risk factor interventions in primary care. Summary of research evidence. Am J Prev Med 2004:27(2 Suppl):61-79.

3. Whitlock EP, Orleans CT, Pender N, Allan J. Evaluating primary care behavioral counseling interventions: an evidence-based approach. Am J Prev Med 2002;22:267-84.

4. Ockene JK, Adams A, Hurley TG, Wheeler EV, Hebert JR. Brief physician- and nurse practitionerdelivered counseling for high-risk drinkers: does it work? Arch Intern Med 1995;159:2198-205.

5. Ockene JK, Ockene IS, Quirk ME, et al. Physician training for patient-centered nutrition counseling in a lipid intervention trial. Prev Med 1995;24:563-70.

6. Ockene JK, Wheeler EV, Adams A, Hurley TG, Hebert J. Provider training for patient-centered alcohol counseling in a primary care setting. Arch Intern Med 1997;157:2334-441.

7. Flocke SA, Clark A, Schlessman K, Pomiecko G. Exercise, diet, and weight loss advice in the family medicine outpatient setting. Fam Med 2005;37:41521.

8. Glasgow RE, Eakin EG, Fisher EB, Bacak SJ, Brownson RJ. Physician advice and support for physical activity: results from a national survey. Am J Prev Med 2001;21:189-96.

9. Glasgow RE, Emmons KM. How can we increase translation of research into practice? Types of evidence needed. Annu Rev Public Health 2007;28: $413-33$.

10. Yarnall KS, Pollak KI, Ostbye T, Krause KM, Michener JL. Primary care: is there enough time for prevention? Am J Public Health 2003;93:635-41.

11. Ware JE, Brook RH, Davies AR, Lohr KN. Choosing measures of health status for individuals in general populations. Am J Public Health 1981;71:620-5.

12. Ware JE, Kosinski M, Keller SD. SF-12: How to score the SF-12 Physical and Mental Health Summary Scales, second edition. Boston (MA): The Health Institute, New England Medical Center; 1995.

13. Sciamanna CN, Goldstein MG, Marcus BH, Lawrence K, Pinto BM. Accuracy of recall of exercise counseling among primary care patients. Prev Med 2004;39:1063-7.

14. Safran DG, Kosinski M, Tarlov AR, et al. The Primary Care Assessment Survey: tests of data quality and measurement performance. Med Care 1998;36: 728-39.

15. Whaley MH (editor), American College of Sports Medicine. ACSM's guidelines for exercise testing and prescription. Baltimore (MD): Lippincott Williams \& Wilkins; 2006.

16. Centers for Disease Control and Prevention. Adult participation in recommended levels of physical activity-United States, 2001 and 2003. MMWR Morb Mortal Wkly Rep 2005;54:1208-12.

17. US Public Health Service. Treating tobacco use and dependence-a systems approach. A guide for health care administrators, insurers, managed care organizations, and purchasers. 2000. Available at http:// www.surgeongeneral.gov/tobacco/systems.htm. Accessed 21 January 2008.

18. Maciosek MV, Edwards NM, Coffield AB, et al. Priorities among effective clinical preventive services: methods. Am J Prev Med 2006;31:90-6.

19. Maciosek MV, Coffield AB, Edwards NM, Flottemesch TJ, Goodman MJ, Solberg LI. Priorities among effective clinical preventive services: results of a systematic review and analysis. Am J Prev Med 2006;31:52-61.

20. Flocke SA, Stange KC. Direct observation and patient recall of health behavior advice. Prev Med 2004;38:343-9.

21. Writing Group for the Activity Counseling Trial Research Group. Effects of physical activity counseling in primary care: The Activity Counseling Trial: a randomized controlled trial. JAMA 2001;286:67787.

22. Fortier MS, Sweet S, OSullivan TL, Williams GC. A self-determination process model of physical activity adoption in the context of a randomized controlled trial. Psychology of Sport \& Exercise 2007;8:741-57.

23. Lorig K, Lubeck D, Kraines RG, Seleznick M, Holman HR. Outcomes of self-help education for pa- 
tients with arthritis. Arthritis and Rheumatism 1985; 28:680-5.

24. Lorig K, Ritter PL, Plant K. A disease-specific selfhelp program compared with a generalized chronic disease self-help program for arthritis patients. Arthritis \& Rheumatism 53(6):950-7, 2005 December 15.

25. Deci EL and Ryan RM. Intrinsic motivation and selfdetermination in buman bebavior. New York: Plenum; 1985.

26. Williams GC. Improving patients' health through supporting the autonomy of patients and providers. In: Deci EL and Ryan RM, editor. Handbook of selfdetermination research. Rochester, NY: University of Rochester Press; 2002. p. 233-54.

27. Logsdon DN, Lazaro CM, Meier RV. The feasibility of behavioral risk reduction in primary medical care. American Journal of Preventive Medicine 5(5): 249-56, 1989 September.

28. Fiore MC, Hatsukami DK, Baker TB. Effective tobacco dependence treatment. JAMA 288(14):176871, 2002 October 9.

29. US Preventive Services Task Force. Clinician's handbook for preventive services, 2 nd ed. International Medical Publishing 1998;2005.
30. Walsh JM, Swangard DM, Davis T, McPhee SJ. Exercise counseling by primary care physicians in the era of managed care. Am J Prev Med 1999;16: 307-13.

31. Swinburn BA, Walter LG, Arroll B, Tilyard MW, Russell DG. The green prescription study: a randomized controlled trial of written exercise advice provided by general practitioners. Am J Public Health 1998;88:288-91.

32. Pinto BM, Goldstein MG, Ashba J, Sciamanna CN, Jette A. Randomized controlled trial of physical activity counseling for older primary care patients. Am J Prev Med 2005;29:247-55.

33. Levy BT, Williamson PS. Patient perceptions and weight loss of obese adults. J Fam Pract 1988;27: 285-90.

34. Galuska DA, Will JC, Serdula MK, Ford ES. Are health care professionals advising obese patients to lose weight? JAMA 1999;282:1576-8.

35. Kreuter MW, Chheda SG, Bull FC. How does physician advice influence patient behavior? Evidence for a priming effect. Arch Fam Med 2000;9:426-33.

36. Taira DA, Safran DG, Seto TB, Rogers WH, Tarlov AR. The relationship between patient income and physician discussion of health risk behaviors. JAMA 1997;278:1412-7. 